\title{
Preterm birth: seven-year retrospective study in a single centre population
}

\author{
Roberta Granese ${ }^{1}$, Eloisa Gitto ${ }^{2}$, Gabriella D'Angelo ${ }^{2,6^{*}}$ (D), Raffaele Falsaperla ${ }^{3}$, Giovanni Corsello ${ }^{4}$, \\ Donatella Amadore ${ }^{1}$, Gloria Calagna ${ }^{5}$, Ilaria Fazzolari ${ }^{1}$, Roberta Grasso ${ }^{1}$ and Onofrio Triolo ${ }^{1}$
}

\begin{abstract}
Background: Preterm birth is a health and social problem, considered the leading cause of neonatal mortality worldwide. It is associated with higher rates of neurodevelopmental morbidity, sensorineural impairments and other complications. The aim of the study was to describe the incidence and the major risk factors associated with preterm birth.

Methods: We performed a single center, observational and retrospective Cohort study in the Division of Obstetrics and Gynaecology, University Hospital "G. Martino", Messina. Clinical records of all pregnant women who delivered from 1st January 2010 to 31 of December 2016 were collected.

Results: In the 7 years considered, a total of 7954 pregnant women were included in our study. The majority of all preterm births were due to infants born late preterm (71.83\%), 26.45\% were due to preterm and $1.72 \%$ to extremely preterm. The preterm cohort had a higher proportion of history of preterm delivery $(p<0.0001)$, and unmarried $(p=0.003)$ and underweight or obese patients $(p<0.0001)$. In addition, prematurity was associated with presence of uterine anomalies $(p<0.0001)$, vaginal/urinary infections $(p=0.02)$, poli/oligohydramnios $(p<0.0001)$, maternal diabetes $(p=0.004)$,

hypertension $(p<0.0001)$, short cervical length $(p<0.0001)$.
\end{abstract}

Conclusions: We suggest prompt identification of all risk factors associated with preterm birth to apply immediate and appropriate specific interventions.

Keywords: Birth, Prematurity, Risk factors, Cervical length, Trans-vaginal cervical screening

\section{Background}

Preterm birth (PTB) is a serious health and social problem, considered the leading cause of neonatal mortality worldwide $[1,2]$. It is associated with higher rates of neurodevelopmental morbidity, sensorineural impairments and other complications of the respiratory, gastrointestinal and renal systems. Epidemiologic evidence also suggests that preterm babies have a significantly increased risk of many chronic degenerative diseases in adulthood, including coronary heart disease, stroke, hypertension, and type II diabetes mellitus [3]. The incidence rates are higher in underdeveloped

\footnotetext{
* Correspondence: gabdangelo@unime.it

${ }^{2}$ Neonatal and Pediatric Intensive Care Unit, Department of Human

Pathology of Adult and Childhood "G. Barresi", University Hospital "G.

Martino", via Consolare Valeria 1, Gazzi, Messina, Italy

${ }^{6}$ Department of Clinical and Experimental Medicine, University of Messina,

Messina, Italy

Full list of author information is available at the end of the article
}

countries (11.8\%) compared to those most developed (9.3\%) [4]. The high incidence of this condition even in most developed countries is due to the fact that even though the incidence of preterm delivery is decreasing for greater prevention of known risk factors, it is also increasing due to iatrogenic PTB [5], an improvement of reproductive technology with, consequently, multiple gestations and also an increased maternal age [6].

According to World Health Organization (WHO), preterm birth is defined as any birth before 37 completed weeks of gestation [7]. A decreasing gestational age is associated with increasing complications for premature babies. The gestational age cut off used to distinguish a PTB from spontaneous abortion varies by geographic areas. In our study the cut off considered is 21 weeks and 5 days, as suggested by "Florence Card" in 2008 [8] and reported in the protocol of our Hospital. In the US, for example, 20 weeks is used as the lower gestational 
age limit [9], while in other regions, especially lower and middle income countries, 28 weeks is often used as the lower limit [9]. We must therefore consider the lower gestational age cut off when we compare PTB rates between different geographic areas.

The research carried out and the preventive measures adopted in this field over the years have allowed a reduction of the incidence of PTB demonstrating the importance of identifying the risk factors associated with this condition [10].

The aim of this study was to assess the trend of the incidence of preterm birth and the major risk factors, combining both maternal risk factors (RFs) and cervical length $(\mathrm{CL})$ and with the inclusion in our cohort of women with a history of previous PTB.

\section{Methods}

We performed a single center, observational and retrospective Cohort study in the Division of Obstetrics and Gynaecology, University Hospital "G. Martino", Messina, Italy. As a standard protocol, each patient, on admission, signed an informed consent allowing data collection for research purposes. The study design was in accordance with the Helsinki Declaration and was approved by the Institutional Review Board of the University Hospital involved. All the design, analysis, interpretation of data, drafting and revisions followed the guidelines for reporting observational studies (STROBE) [11], available through the EQUATOR (Enhancing the QUAlity and Transparency Of health Research) network (http://www.equatornetwork.org/).

Clinical records of all pregnant women who delivered from 1st January 2010 to 31 of December 2016 were collected, while patients who underwent cerclage, pregnancies complicated by intrauterine fetal death or serious fetal malformation and multiple pregnancies have been excluded (Table 1).

We defined preterm birth all the deliveries before 36 $+6 / 7$ week/day of gestation according to the WHO [7]. We planned to look at subgroups of PTBs, such as extremely early preterm (i.e. $21+5-23+6$ ), preterm (i.e. $24-33+6$ ) and late preterm (i.e. $34-36+6$ ) [12].

\section{Statistical analysis}

Statistical analysis was conducted using SAS version 9.2 (SAS Institute Inc., Cary, NC, USA). Continuous variables are presented as mean (SD) or median (interquartile range), where appropriate, and categorical variables as frequencies and percentages. Differences between control and preterm cases were assessed using unpaired Student's t-tests or Mann-Whitney U test, as appropriate. The chi-square test was used to compare frequencies. Bivariate associations were tested by Spearman correlation. A conservatively adjusted a priori alpha was set at $p<.01$ due to multiple comparisons.

\section{Results}

A total of 8179 pregnant women were admitted to deliver in our Institution in the period considered [Fig. 1a]. Seven thousand nine hundred fifty-four cases were included in our study and 225 were excluded as they did not fall within the inclusion criteria. The preterm cases were 639 (7.8\%). Demographic and clinical characteristics of the preterm cohort and the term controls are shown in Table 1.

The rate of preterm birth in our Institution has shown a relatively stable or a slightly decreasing trend from 7.2 to $6.9 \%$ over the 7 year period (Fig. 1b).

The majority of all preterm births were due to infants born late preterm, $71.83 \%(n=459), 26,45 \%(n=169)$ were due to preterm and $1.72 \%(n=11)$ to extremely preterm (Fig. 2).

The preterm cohort showed a higher proportion of history of a prior spontaneous PTB $(p<0.0001)$, unmarried women $(p=0.003)$ and underweight or obese patients $(\mathrm{p}<0.0001)$. In addition, PTB was associated with presence of uterine anomalies $(p<0.0001)$, vaginal/urinary infections $(p=0.02)$, poli-oligodramnios $(p<0.0001)$, maternal diabetes $(p=0.004)$ and hypertension $(p<0.0001)$.

The median value of cervical length measured from 16th to 24th week of pregnancy was $31 \mathrm{~mm}$ in cases who delivered preterm and $38 \mathrm{~mm}$ in controls, demonstrating a significant difference between the two groups $(p<0.0001)$ (Table 1 e Fig. 2). The CL measurement, using a cut off of $25 \mathrm{~mm}$ according to the SIEOG guidelines (28), showed a sensibility of $78 \%$, demonstrating to be an adequate screening test for the women at risk of PTB, even if the specificity was only $3 \%$.

Among PTB, cervical length positively correlated with gestational age $(\mathrm{r}=0.42, \mathrm{p}<0.0001)$ (Fig. 2). A sub-analysis of preterm birth categories based on gestational age showed a stronger correlation between gestational age and cervical length among preterm and extremely preterm $(\mathrm{r}=0.50, p=$ 0.0002 ), while no correlation was found among late preterm $(\mathrm{r}=0.01, p=0.85)$. Among PTB, cervical length correlated with older mothers $(\mathrm{r}=0.21, p=0.025)$. No other correlations were found.

\section{Discussion}

In our observational and retrospective Cohort study of pregnant women admitted to an Obstetric Department in Southern Italy, the incidence of preterm birth was $7.8 \%$. The rate of preterm birth decreased from 7.2 to $6.9 \%$ (Fig. 1b), together with an increase of births in our Hospital (Fig. 1a). However, the value remains high, considering that preterm birth is associated with most of 
Table 1 Clinical and demographic characteristics of control and preterm cases

\begin{tabular}{|c|c|c|c|c|}
\hline \multicolumn{2}{|l|}{ Characteristics } & Controls $(n=7315)$ & Preterm Cases $(n=639)$ & $p$-value \\
\hline \multicolumn{2}{|c|}{ Maternal age (years), mean (SD) } & $31.87(6.04)$ & $31.68(5.65)$ & 0.025 \\
\hline \multicolumn{2}{|c|}{ Pre-pregnancy weight $(\mathrm{kg})$, mean (SD) } & $63.44(13.98)$ & $63.73(13.32)$ & 0.2 \\
\hline \multirow[t]{4}{*}{ Maternal BMI, n (\%) } & Underweight & $293(4)$ & $102(16)$ & \multirow[t]{4}{*}{$<0.0001^{*}$} \\
\hline & Normal & $4462(61)$ & $262(41)$ & \\
\hline & Overweight & $1682(23)$ & $51(8)$ & \\
\hline & Obesity & $878(12)$ & $224(35)$ & \\
\hline \multirow[t]{2}{*}{ Marital status, n (\%) } & Married & $5998(82)$ & $492(77)$ & \multirow[t]{2}{*}{$0.003^{*}$} \\
\hline & Unmarried & $1317(18)$ & $147(23)$ & \\
\hline \multirow[t]{2}{*}{ Parity } & Nulliparous & $4096(56)$ & $367(57.5)$ & \multirow[t]{2}{*}{0.5} \\
\hline & Parous & $3219(44)$ & $272(42.5)$ & \\
\hline \multicolumn{2}{|c|}{ Prior history of PTB, Yes/No, n (\%) } & 256/7059 (3.5/96.5) & $40 / 428(8.5 / 91.5)$ & $<0.0001^{*}$ \\
\hline \multicolumn{5}{|c|}{ Treatment for cervical dysplasia } \\
\hline \multicolumn{2}{|l|}{ Yes/No, n (\%) } & $110 / 7205(1.5 / 98.5)$ & $13 / 626(2 / 98)$ & 0.2 \\
\hline \multicolumn{2}{|c|}{ Cervical Length (mm), median (IQR) } & $38(34-42)$ & $31(23-37)$ & $<0.0001^{*}$ \\
\hline \multicolumn{2}{|c|}{ Uterine Anomalies, Yes/No, n (\%) } & $66 / 7249(0.9 / 99.1)$ & 22/617 (3.4/96.6) & $<0.0001^{*}$ \\
\hline \multicolumn{2}{|c|}{ Vaginal/Urinary Infections Yes/No, n (\%) } & $1463 / 5852(20 / 80)$ & $115 / 524(18 / 82)$ & $0.02^{*}$ \\
\hline \multicolumn{5}{|l|}{ Poly/oligohydramnios } \\
\hline \multirow[t]{3}{*}{ Yes/No, n (\%) } & No & 7096 (97) & $518(81)$ & \multirow[t]{3}{*}{$<0.0001^{*}$} \\
\hline & Polyhydramnios & $37(0.5)$ & $13(2)$ & \\
\hline & Oligohydramnios & $182(2.5)$ & $102(9)$ & \\
\hline \multicolumn{2}{|c|}{ Hypertension, Yes/No, n (\%) } & $366 / 6949(5 / 95)$ & $115 / 524(18 / 82)$ & $<0.0001^{*}$ \\
\hline \multicolumn{2}{|c|}{ Thyroid disease, Yes/No, n (\%) } & $1024 / 6291(14 / 86)$ & $83 / 556(13 / 87)$ & 0.5 \\
\hline \multicolumn{2}{|c|}{ Diabetes, Yes/No, n (\%) } & $732 / 6583(10 / 90)$ & $93 / 546(14.5 / 85.5)$ & $0.004^{*}$ \\
\hline \multicolumn{2}{|c|}{ Maternal Surgery, Yes/No, n (\%) } & $2677 / 4638(36.6 / 63.4)$ & $252 / 387(39.5 / 60.5)$ & 0.2 \\
\hline \multicolumn{2}{|c|}{ Psychological Disorders, Yes/No, n (\%) } & $37 / 7278(0.5 / 99.5)$ & $7 / 632(1.1 / 98.9)$ & 0.3 \\
\hline \multicolumn{2}{|c|}{ Smoking, Yes/No, n (\%) } & $658 / 6657(9 / 91)$ & $51 / 588(8 / 92)$ & 0.5 \\
\hline
\end{tabular}
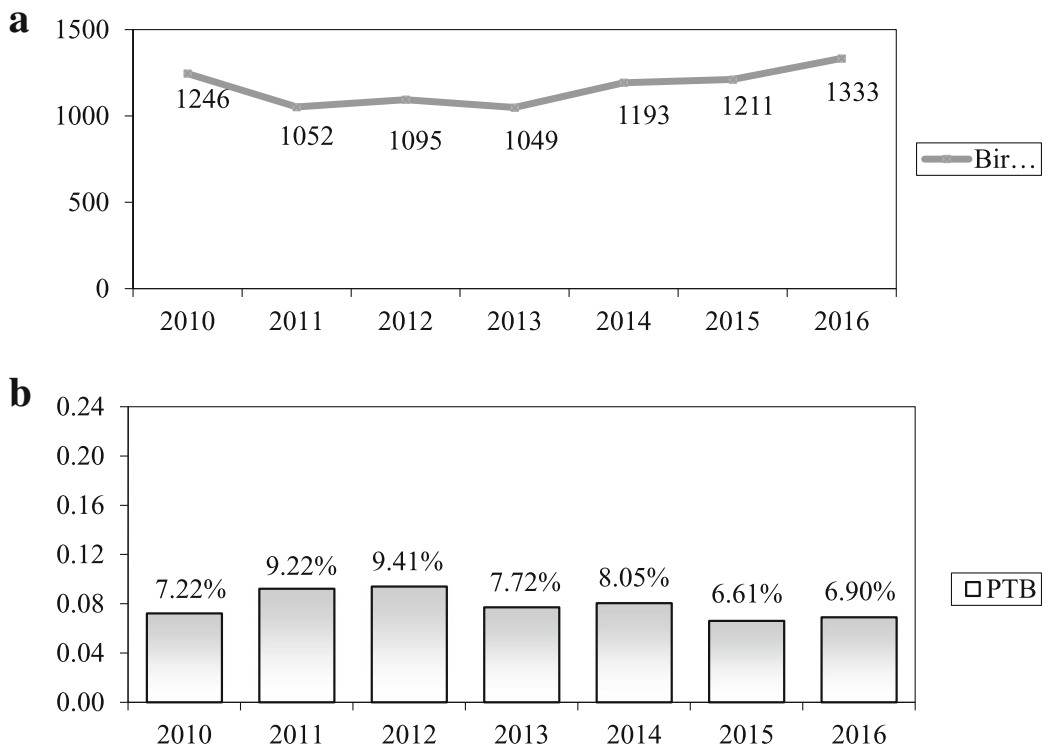

Fig. 1 a Trends of annual births in our Institution. b Trends of preterm birth annual cases in our Institution 


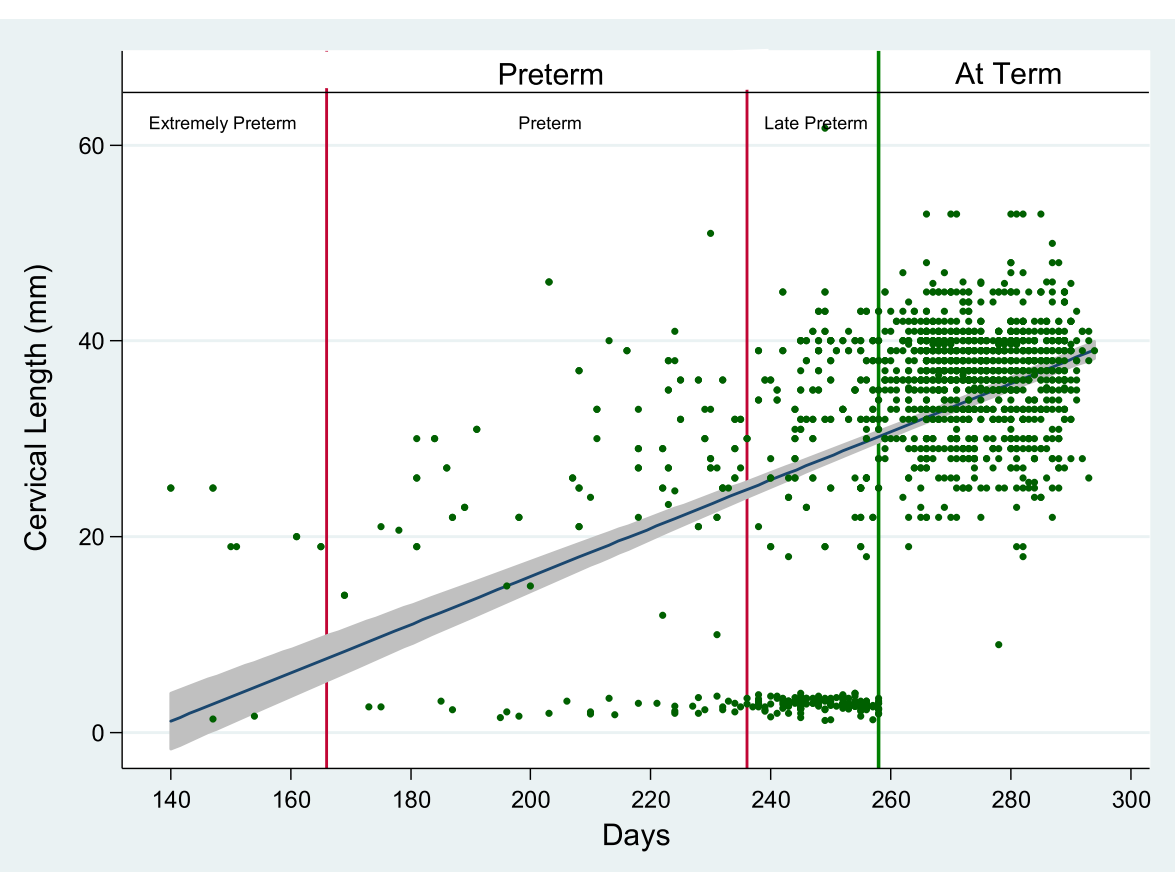

Fig. 2 Correlation between cervical length and gestation at birth in preterm cases and controls

the pregnancy-related mortality and and short and long-term disability [2].

The slightly decreasing rate of PTB could be, partially, explained with the utmost attention in the prevention of this condition based on the known risk factors. Many features are associated with PTB, such as maternal demographic characteristics [6], nutritional status/ physical activity, prior ob/gyn history, current pregnancy characteristics (i.e. vaginal bleeding, uterine contractions, poly/oligohydramnios, psychological problems, use of drugs or infection) [13-16]. Among these risk factors, history of PTB and short CL are considered the most important predictive factors [17-20]. Particularly, a short cervix in the second trimester (i.e. a cervix measure $<15 \mathrm{~mm}$, in a single pregnancy) [21] is a powerful predictor of spontaneous PTB, regardless of obstetrical history [22].

In our analysis, we only included data on risk factors, which were clearly reported in all clinical records or significantly present in the folders. We report a significant association between PTB and risk factors such as vaginal/urinary infections, underweight or obese patients, unmarried status, the presence of uterine anomalies, poly/oligohydramnios, hypertension, diabetes, a history of PTB and, finally, a short cervical length. Many of these risk factors could be identified with a good medical history and also treated, leading to an improvement of the risk at the beginning of pregnancy.

In our study, particular attention has been given to CL measurement. While "late preterm" cases demonstrated a large variability of CL values, the "preterm" and "very early" preterm cases were more correlated with short cervical length, independently to a history of previous preterm. This data, confirming previous studies [23], assumes that cervical length helps to identify better the case at risk for early and very early PTB. Probably, in late preterm cases, other risk factors should be also considered, such as maternal disease (i.e.: severe hypertension resistant to medical therapy) or fetal pathological conditions which prompt the gynaecologist to induce labor, determining an iatrogenic PTB.

Our findings suggest a universal cervical screening (i.e. not only for women at higher risk) should be performed in order to discover, at an early stage, asymptomatic women with a short cervix (2-5\% of total) [24] and to administer a preventive therapy $[25,26]$. The CL measurement could be taken during the midtrimester ultrasound screening by all obstetric ultrasonographers who have received appropriate training. Transvaginal ultrasound is safe, and when performed by trained operators results are reproducible with a relatively low inter-observer variation rate of $5-10 \%$ [27]. Currently, the cervical measurement is performed only in women with a higher risk of preterm birth or with symptoms of preterm labour (to reduce hospitalization for tocolysis) [28, 29], in women who undergo cervical cerclage or in twin pregnancies [28]. Data on the utility of the cervical length measurement is reported in many papers $[23,25,28-31]$ but, according to the guidelines of the Italian Society of Ultrasound in Obstetrics and Gynaecology (SIEOG), the use of ultrasound for the evaluation of the uterine cervix in a low-risk 
population is not supported by sufficient scientific evidence [28]. This statement has been confirmed in the NICE (National Institute for Health and Care Excellence) guideline [32] and in the SCOG (Society of Obstetricians and Gynaecologists of Canada) guidelines, which do not consider the consequent therapeutic interventions valid [33]. Cervical screening is one tool that can be utilized to identify women at increased risk in order to allow for interventions to prevent, delay, or prepare for preterm births, without the need to undergo to biochemical testing for specific markers for preterm labour. Many authors have questioned if universal midtrimester transvaginal CL screening meets the criteria outlined by the $\mathrm{WHO}$ of an adequate screening test [34]. Some authors $[35,36]$ concluded that this screening for women with a singleton gestation, followed by treatment with vaginal progesterone for those with a short cervix, meets all 10 criteria outlined by the $\mathrm{WHO}$ for endorsing the implementation of a screening test in clinical medicine [34].

Also the recent Italian guidelines of the Confalonieri Ragonese Foundation recommend performing a cervical measurement during the second trimester ultrasound screening (19-23.6 weeks) of all pregnant women and to administer $200 \mathrm{mg}$ of Progesterone to those women with a cervix between 10 and $20 \mathrm{~mm}$ [21]. This suggestion is motivated by the results of a systematic review where it was shown that Progesterone administration to a sample of women without a history of PTB and with a cervix between 10 and $20 \mathrm{~mm}$ demonstrated a significant reduction of PTB and neonatal morbidity, while in the subgroup with a cervical length $<10 \mathrm{~mm}$ or between 21 and $25 \mathrm{~mm}$ did not give any benefits in prevention of PTB [37]. Another recent systematic review and meta-analysis [26] from randomised controlled trials confirmed that vaginal progesterone was associated with a significant reduction in the risk of preterm birth, respiratory distress syndrome, composite neonatal morbidity and mortality, birth weight $<1500$ and $<2500 \mathrm{~g}$ and admission to the neonatal intensive care unit. The study reported a reduction of about $40-50 \%$ of neonatal death, respiratory distress syndrome, intraventricular haemorrhage and proven neonatal sepsis. Moreover, maternal adverse events, congenital anomalies and adverse neurodevelopmental and health outcomes at 2 years of age did not report any difference between groups, confirming that vaginal progesteron is, at the same time, efficacious and safe [26].

We also use to administrate vaginal progesterone in all the cases at risk for a short CL. This procedure has probably contributed, together with all other preventive measures, to the slight reduction of preterm birth over the years in our Hospital.

\section{Conclusions}

Based on our results, we suggest prompt identification of all risk factors associated with preterm birth to apply immediate and appropriate specific interventions.
We also recommend, confirming the evidence of other studies [26, 38-40], a transvaginal CL measurement during the midtrimester ultrasound screening, in order to identify the women most at risk who could benefit of a progesterone therapy, without the need to undergo to furthers biochemical testing for specific markers for PTB.

All these procedures could reduce the rate of PTB and the associated neonatal morbidity and mortality.

\section{Abbreviations}

CL: Cervical length; NICE: National Institute for Health and Care Excellence; PTB: Preterm birth; RFs: Risk factors; SCOG: Society of Obstetricians and Gynaecologists of Canada; SIEOG: Italian Society of Ultrasound in Obstetrics and Gynaecology; WHO: World Health Organization

\section{Acknowledgements \\ The authors gratefully acknowledge the support by families of all these preterm babies.}

\section{Funding}

This research did not receive any specific grant from funding agencies in the public, commercial, or not-for-profit sectors.

Availability of data and materials

Data sharing not applicable to this article as no datasets were generated or analyzed during the current study.

\section{Authors' contributions}

All authors made substantial contributions and approved the final version of the article. RG and EG made substantial contributions in the drafting the article, conception and design of the study, analysis and interpretation of data. RF and GC made substantial contributions in the revising manuscript critically for important intellectual content. DA made substantial contributions in the acquisition of data, analysis and interpretation of data. GD made substantial contributions in the acquisition of data and analysis. GC made substantial contributions in the acquisition of data and analysis. IF made substantial contributions in the acquisition of data and analysis. RG made substantial contributions in the acquisition and interpretation of data. OT made substantial contributions in final approval of the version to be submitted.

\section{Ethics approval and consent to participate}

Yes

\section{Consent for publication}

Yes

\section{Competing interests}

The authors declare that they have no competing interests.

\section{Publisher's Note}

Springer Nature remains neutral with regard to jurisdictional claims in published maps and institutional affiliations.

\section{Author details}

${ }^{1}$ Obstetrics and Gynecology Unit, Department of Human Pathology of Adult and Childhood "G. Barresi", University Hospital "G. Martino", via Consolare Valeria 1, Gazzi, Messina, Italy. ${ }^{2}$ Neonatal and Pediatric Intensive Care Unit, Department of Human Pathology of Adult and Childhood "G. Barresi", University Hospital "G. Martino", via Consolare Valeria 1, Gazzi, Messina, Italy ${ }^{3}$ General Pediatrics and Pediatric Acute and Emergency Unit,

Policlinico-Vittorio-Emanuele University Hospital, University of Catania, Catania, Italy. ${ }^{4}$ Department of Maternal and Child Health, University of Palermo, Palermo, Italy. ${ }^{5}$ Obstetrics and Gynecology Unit, "Villa Sofia Cervello Hospital", University of Palermo, Piazza Salerno 1, Palermo, Italy. ${ }^{6}$ Department of Clinical and Experimental Medicine, University of Messina, Messina, Italy. 
Received: 4 February 2019 Accepted: 29 March 2019

Published online: 11 April 2019

\section{References}

1. Saccone G, Perriera L, Berghella V. Prior uterine evacuation of pregnancy as independent risk factor for preterm birth: a systematic review and metaanalysis. Am J Obstet Gynecol. 2016;214:572-91.

2. Mathews TJ, MacDorman MF. Infant mortality statistics from the 2006 period linked birth/infant death data set. Natl Vital Stat Rep. 2010;58:1-31.

3. Saigal S, Doyle LW. An overview of mortality and sequelae of preterm birth from infancy to adulthood. Lancet. 2008;371:261-9.

4. Martin JA, Kochanek KD, Strobino DM, Guyer B, MacDorman MF. Annual summary of vital statistics 2003. Pediatrics. 2005;115:619-34.

5. Granese R, Calagna G, Sollano A, et al. Data comparison between pharmacological induction of labour and spontaneous delivery. A single centre experience. Ginekol Pol. 2016;87:697-700

6. Ciancimino L, Laganà AS, Chiofalo B, Granese R, Grasso R, Triolo O. Would it be too late? A retrospective case-control analysis to evaluate maternal-fetal outcomes in advanced maternal age. Arch Gynecol Obstet. 2014;290:1 109-14.

7. World Health Organization WHO. Recommended definitions, terminology and format for statistical tables related to the perinatal period and use of a new certificate for cause of perinatal deaths. Modifications recommended by FIGO as amended October 14, 1976. Acta Obstet Gynecol Scand. 1977; 56:247-53.

8. I grandi prematuri. Note bioetiche. Comitato Nazionale per la Bioetica. La "Carta di Firenze", 2008. Presidenza del Consiglio dei Ministri.

9. Vincenzo Berghella. Preterm Birth: Prevention and Management. John Wiley \& Sons, 19 gen 2010.

10. Suhag A, Berghella V. Short cervical length dilemma. Obstet Gynecol Clin N Am. 2015:42:241-54.

11. Von Elm E, Altman DG, Egger M, Pocock SJ, Gøtzsche PC, Vandenbroucke JP. STROBE initiative. The strengthening the reporting of observationa studies in epidemiology (STROBE) statement: guidelines for reporting observational studies. Lancet. 2007;370:1453-7.

12. Berghella V. Preterm birth prevention. In: Berghella V, editor. Obstetric Evidence Based Guidelines. London- New York; 2012. p. 150-64.

13. Goldenberg RL, Culhane JF, lams JD, Romero R. Ep-idemiology and causes of preterm birth. Lancet. 2008;371:75-84.

14. Mercer BM, Goldenberg RL, Das A, et al. The preterm predic $\neg$ tion study: a clinical risk assessment system. Am J Obstet Gynecol. 1996;174:1885-95.

15. American College of Obstetricians and Gynecologists. ACOG Practice Bulletin. Assessment of risk fac $\neg$ tors for preterm birth. Clinical management guideᄀlines for obstetrician-gynecologists. Number 31, October 2001. (Replaces Technical Bulletin num-ber 206, June 1995; Committee Opinion num-ber 172, May 1996; Committee Opinion number 187, September 1997; Committee Opinion num $\neg$ ber 198, February 1998; and Committee Opin-ion number 251, January 2001). Obstet Gynecol. 2001;98:709-16.

16. Hoyme UB. Pragmatic prevention of preterm birth and evidence based medicine. Arch Gynecol Obstet. 2016;294:1-3.

17. Adams MM, Elam-Evans LD, Wilson HG, Gilbertz DA. Rates of and factors associated with recur $\neg$ rence of preterm delivery. JAMA. 2000;283:1591-6.

18. Esplin MS, O'Brien E, Fraser A, et al. Estimating recurrence of spontaneous preterm delivery. Obstet Gynecol. 2008;112:516-23.

19. Durnwald C, Walker H, Lundy J, lams JD. Rates of recurrent preterm birth by obstetrical history and cervical length. Am J Obstet Gynecol. 2005;193:1170-4.

20. Jakobsson M, Gissler M, Sainio S, Paavonen J, Tapper AM. Preterm delivery after surgical treatment for cervical intraepithelial neoplasia. Obstet Gynecol. 2007;109:309-13.

21. Gestione del parto pretermine. Fondazione Confalonieri Ragonese su mandato SIGO, AOGOI, AGUI 2016. Facilitatore A. Regalia (www.sigo.it).

22. Leung TN, Pang MW, Leung TY, Poon CF, Wong SM, Lau TK. Cervical length at 18-22 weeks of gesta-tion for prediction of spontaneous preterm deliv $\neg$ ery in Hong Kong Chinese women. Ultrasound Obstet Gynecol. 2005; 26:713-7.

23. Granese R, Mantegna S, Mondello S, et al. Preterm birth: incidence, risk factors and second trimester cervical length in a single center population. A two-year retrospective study. Eur Rev Med Pharmacol Sci. 2017;21:4270-7.

24. Martin JA, Hamilton BE, Sutton PD, et al. Centers for Disease Control and Prevention National Center for Health Statistics National Vital Statistics sys $\neg$ tem. Births: final data for 2007. Natl Vital Stat Rep. 2010;58:1-85.
25. Romero R, Conde-Agudelo A, Da Fonseca E, et al. Vaginal progesterone for preventing preterm birth and adverse perinatal outcomes in singleton gestations with a short cervix: a meta-analysis of individual patient data. Am J Obstet Gynecol. 2017;218:161-80.

26. Saccone G, Simonetti B, Berghella V. Transvaginal ultrasound cervical length for prediction of spon $\neg$ taneous labour at term: a systematic review and meta-analysis. BJOG. 2016;123:16-22.

27. Owen J, lams JD. What we have learned about cervical ultrasound. Semin Perinatol. 2003;27:194-203 National Institute of Child Health and Human Development Maternal-Fetal Medicine Units Network.

28. Linee Guida Societa' Italiana di Ecografia Ostetrico Ginecologica, SIEOG 2015. Gruppo Editoriale EDITEAM

29. Berghella V, Palacio M, Ness A, Alfirevic Z, Nicolaides KH, Saccone G. Cervical length screening for prevention of preterm birth in singleton pregnancy with threatened preterm labor: systematic review and meta-analysis of randomized controlled trials using individual patient-level data. Ultrasound Obstet Gynecol. 2017:49:322-9.

30. Navathe R, Saccone G, Villani M, et al. Decrease in the incidence of threatened preterm labor after implementation of transvaginal ultrasound cervical length universal screening. J Matern Fetal Neonatal Med. 2018;5:1-6.

31. Van der Ven J, van Os MA, Kazemier BM, et al. The capacity of midpregnancy cervical length to predict preterm birth in low-risk women: a national cohort study. Acta Obstet Gynecol Scand. 2015;94:1223-34.

32. NICE. Preterm labour and birth: methods, evidence and recommendations. Guidelines 2015;25.

33. Lim K. SOGC. Clinical practice guideline. Ultrasonographic cervical length assessment in predicting preterm birth in singleton pregnancies. J Obstet Gynaecol Can. 2011;33:486-99.

34. World Health Organization Fact Sheet \#363. November 2014. Available at:http:// www.who.int/mediacentre/factsheets/fs363/en/. Accessed 16 Mar 2016.

35. Combs CA. Vaginal progesterone for asymptomatic cervical shortening and the case for universal screening of cervical length. Am J Obstet Gynecol. 2012:206:101-3.

36. Khalifeh A, Berghella V. Universal cervical length screening in singleton gestations without a previous preterm birth: ten reasons why it should be implemented. Am J Obstet Gynecol. 2016;214:603.

37. Romero R, Nicolaides $\mathrm{K}$, Conde-Agudelo $\mathrm{A}$, et al. Vaginal progesterone in women with an asymptomatic sonographic short cervix in the midtrimester decreases preterm delivery and neonatal morbidity: a systematic review and metaanalysis of individual patient data. Am J Obstet Gynecol. 2012;206:124 e1-19.

38. FIGO Working Group on Best Practice in Maternal-Fetal Medicine International Federation of Gynecology and Obstetrics. Best practice in maternal-fetal medicine. Int J Gynaecol Obstet. 2015;128:80-2.

39. Romero R, Nicolaides KH, Conde-Agudelo A, et al. Vaginal progesterone decreases preterm birth $<34$ weeks of gestation in women with a singleton pregnancy and a short cervix: an updated meta-analysis including data from the OPPTIMUM study. Ultrasound Obstet Gynecol. 2016;48:308-17.

40. Vintzileos AM, Visser GH. Interventions for women with mid-trimester short cervix: which ones work? Ultrasound Obstet Gynecol. 2017;49:295-300.

\section{Ready to submit your research? Choose BMC and benefit from:}

- fast, convenient online submission

- thorough peer review by experienced researchers in your field

- rapid publication on acceptance

- support for research data, including large and complex data types

- gold Open Access which fosters wider collaboration and increased citations

- maximum visibility for your research: over $100 \mathrm{M}$ website views per year

At $\mathrm{BMC}$, research is always in progress.

Learn more biomedcentral.com/submissions 